\title{
An Alternative Teaching Method for the Regulation of the Immune Response
}

\author{
Ana Cecília Michel da Rosa, Luiz Felipe Osowski, Andréa Goya Tocchetto, Carlos Eduardo \\ Niederauer, Cristiane Maria Benvenuto Andrade and Maria Lúcia Scroferneker
}

\author{
Department of Mic robiology \\ Universidade Federal do Rio Grande do Sul \\ Porto Alegre \\ Brazil
}

\begin{abstract}
Purpose: Our teaching experience has shown that dealing with the molecular aspects of the immune response regulation poses several difficulties. Therefore, we developed a panel board to verify whether or not this active-learning exercise could enhance students' learning and arouse their interest in subjects that are basically theoretical and complex.

Methods: Twenty cardboard pieces labeled with the names of major regulators of the immune response and three panel boards with explanations on how major regulators work. Students had to match the cardboard pieces with the corresponding explanation.

Results: One hundred forty students participated in this study. The overall response of the students to the game was very positive: $95.71 \%$ considered the panel board interesting and $95 \%$ said the panel board facilitated the understanding of the subject matter. The students' grades significantly improved $(\mathrm{P}<0.0001)$.

Conclusion: The results obtained show the importance of using the panel board when trying to approach a subject that is vast and complex not only for students but also for professors.
\end{abstract}

Key Words: Immune Response; Regulation; Learning; Game

Regulation of the immune response is a physiologic process that takes place whenever the immune system encounters an antigen, involving both the humoral and the cell-mediated branch. Every time an antigen is introduced, important regulatory decisions determine the branch of the immune system to be activated, the intensity of the response, and its duration. ${ }^{1}$

Our teaching experience has shown that dealing with molecular and biochemical aspects of the $\mathrm{m}$ mune system poses several difficulties. At the School of Medicine of Universidade Federal do Rio Grande do Sul, Brazil, medical immunology is taught during the fourth semester, along with courses such as $\mathrm{Pa}$ thology and Introduction to Clinical Practice, which emphasize the practice of Medicine. The comparison between medical immunology and these other subjects may discourage students from the study of more theoretical subjects. We previously developed teaching aids, for example, a poster for the study of the complement system, ${ }^{2}$ and a game for the study of cellular and humoral responses. ${ }^{3}$ In both cases, we had satisfactory results. Siqueira et al. ${ }^{4,5}$ developed two methods for teaching biochemistry, which they called "The Krebs Cycle Game" and "The Dynamic Metabolic Diagrams". Both were games that involved a logical sequence of thoughts, and proved valid as a tool for stimulating the learning process. Another game approach using case-based, smallgroup discussion format to teach ethics in medical school was described by Baldor et al. in Academic Medicine, in 2001. ${ }^{6}$ Finally, Moy et al. ${ }^{7}$ developed an educational game in pulmonary physiology for firstyear medical students based on a popular television game show, evincing that the educational tool enhanced students' learning process and their ability to understand and retain information.

This study presents a panel board on the regulation of the immune responses as a teaching aid. Our aim was to verify whether this active-learning exe $r$ cise could enhance students' learning and arouse their interest in subjects that are basically theoretical and complex, thus stimulating their memory and creativity. 
Da Rosa ACM, Osowski LF, Tocchetto AG, Niederauer CE, Andrade $\mathrm{CMB}$, Scroferneker ML. An alternative teaching method for the regulation of the Immune response

\section{Materials and Methods}

About the Game - The "Immune System Regulation game" was designed for fourth semester medical students taking the immunology course.

The game consisted of 20 cardboard pieces $(5 \times 5$ $\mathrm{cm}$ ) labeled with the names of major regulators of the immune response and three panel boards $(50 \mathrm{x} 60 \mathrm{~cm}$ each). Each panel board presented a group of regulators (genetic control, positive and negative regulators) and contained explanations on how major regulators work. Next to each explanation, there was a blank space so that students could fit the cardboard pieces into the corresponding space (Figures. 1-3 see Appendix).

Creating the Game - The panel boards and the cardboard pieces were created by one of the authors (Luiz Felipe Osowski) based on immunology books ${ }^{1,8-10}$ and the illustrations were created by a second author (Andréa Goya Tocchetto) using Microsoft PowerPoint ${ }^{\circledR}$.

Monitors - We selected last-year undergraduate
Med Educ Online [serial online] 2003;8:13. Available from http://www.med-ed-online.org

medical students, who had volunteered to help develop and apply the game, by sitting them for a written test on Regulation of the Immune Response. A total of 28 students were selected and then trained by the head professor. The topic was brought up in every training session by the head professor and the game was played by the monitors until there were no questions regarding its application. Four sessions were run, with a 7-day interval in between.

Suggestions for Play - One week before playing the game, students were asked to study about the regulation of the immune response and the bibliography was indicated. $1,8-10$

On the day of the game, a review session about the regulatory mechanisms was conducted by the head professor. After that, all students were randomly split into two groups (A and B) and were asked to answer a test (Pretest), so that their previous knowledge could be checked. There were two different pretests - test A (Figure 4) and test B (Figure 5) -, both including 10 statements. Students in group A answered pretest $\mathrm{A}$ and students in group B, pretest B. Both groups had the same number of students. All students were asked to mark true or false to each one

Table 1

Evaluation of instrumental materials for Regulation of the Immune Response

\begin{tabular}{|c|c|c|c|c|c|}
\hline Questions & & & $\begin{array}{l}\text { Ans } \\
\text { No. } \\
\text { (n= }\end{array}$ & & \\
\hline 1. Is the game interesting? & Yes & 95.71 & $(134)$ & No & $4.28 \quad(6)$ \\
\hline 2. Did the game allow learning the subject matter more easily? & Yes & 95.00 & $(133)$ & No & $5.00 \quad(7)$ \\
\hline 3. Is the subject difficult? & Yes & 92.85 & $(130)$ & No & $7.14(10)$ \\
\hline 4. Was the subject previously studied? & Yes & 75.00 & $(105)$ & No & $25.00(35)$ \\
\hline $\begin{array}{l}\text { 5. Do you think the game improved your knowledge about the } \\
\text { subject? }\end{array}$ & Yes & 91.42 & $(96) \ddagger$ & & \\
\hline 6. Was the recommended literature appropriate? & Yes & 76.19 & $(80) \ddagger$ & & \\
\hline 7. Was the structure of the game clear? & Yes & 100.00 & $(140)$ & No & 0 \\
\hline 8. Was the order of presentation logical? & Yes & 94.28 & $(132)$ & No & $5.71(8)$ \\
\hline 9. Did the activity arouse your interest in the subject matter? & Yes & 60.00 & $(84)$ & No & $40.00(56)$ \\
\hline $\begin{array}{l}\text { 10. After playing the game, did you understand how the regula- } \\
\text { tion of the immune response works? }\end{array}$ & Yes & 95.00 & $(133)$ & No & $5.00 \quad(7)$ \\
\hline 11. Were the illustrations helpful? & Yes & 95.00 & $(133)$ & No & $5.00 \quad(7)$ \\
\hline 12. How do you rate the activity? & Excellent & 25.00 & $(35)$ & & \\
\hline & Good & 75.00 & $(105)$ & & \\
\hline & Regular & 0 & & & \\
\hline & Poor & 0 & & & \\
\hline
\end{tabular}

Evaluation instrument designed to assess the educational tool, including results expressed as rates. Students esponded to the following: the following statements evaluate general aspects of the materials. Mark yes or no and rate the activity considering the way you feel regarding each statement.

$\$ 91.42 \%$ and $76.19 \%$ of 105 students who read the recommended literature. 
Da Rosa ACM, Osowski LF, Tocchetto AG, Niederauer CE, Andrade $\mathrm{CMB}$, Scroferneker ML. An alternative teaching method for the regulation of the Immune response

of the assertions.

Afterwards, students were once again split, but this time, they formed small groups (5 students per group) to enhance student's engagement. Each group had a monitor of the Medical Immunology course to explain the rules and to conduct the game.

Before playing the game, 3 panels about the regulation of the immune response and the 20 cardboard pieces were placed on a desk. The monitors began the game by explaining the regulatory mechanisms (written on the panels) and the students had to associate them with the corresponding cardboard pieces. Every time a student was able to correctly associate the name of the mechanism with the corresponding cardboard piece, he/she scored one point. After all mechanisms were shown, the student with the highest score won the game.

- Monitors completed the session discussing about the subject and clarifying additional doubts.

- The overall time for playing the game and answering the evaluation instruments was 2 hours.

Evaluation - To determine the effectiveness of the educational tool, students were asked to answer a questionnaire (Table 1) and a second test (posttest) after playing the game. Twelve statements were employed on the questionnaire to evaluate four general aspects of the active-learning exercise (goals and objectives, content, motivation and participation, organization and structure). Students were asked to evaluate the extent to which they agreed with the statements by answering yes or no to each question (assertions 1 to 11 ) or rating the activity as excellent, good, regular or poor (assertion 12). The posttests were exactly the same tests used as pretest. Students who answered test A as pretest (group A) were asked to complete test B as posttest and vice-versa. Grades obtained on the pretest and posttests were compared in order to assess students' improvement after playing the game.

Data analysis - The data were analyzed by means of Epi-Info version 6.04d (Center for disease Control and Prevention, Atlanta, GA). Statistical methods employed for this analysis included frequency, mean, variance and standard deviation. A paired t-test was used to analyze pre- and post- intervention change. Results are expressed as means +/standard deviation. For all analyses, a two-tailed $\mathrm{p}$ value of less than 0.05 was considered to indicate statistical significance.

Additionally, we checked whether there were
Med Educ Online [serial online] 2003;8:13. Available from http://www.med-ed-online.org

differences between the grades of students who had read about regulation of the immune response before playing the game and students who had not studied the recommended literature previously. Based on students' reports when answering the questionnaire, we took the tests from these two subgroups and analyzed them separately.

\section{Results}

One hundred forty students attending the fourth semester of Medical School participated in this study. The overall response of the students to the game was very positive. Of the 140 students, 134 (95.71\%) considered the panel board interesting; 133 (95\%) said the panel board facilitated the understanding of the subject matter; $130(92.85 \%)$ considered the subject matter difficult. 105 students $(75 \%)$ reported studying the recommended literature previously to the class; of these 105 students, 96 (91.42\%) have noticed learning improvement and $80(76.19 \%)$ found that the recommended literature was appropriate; As for the presentation of the game, all of the $140 \mathrm{stu}-$ dents $(100 \%)$ found the structure clear; 132 $(94.28 \%)$ said that the order of presentation was also logical; $84(60 \%)$ increased their interest in the subject matter; 133 (95\%) affirmed they understood how regulation of the immune responses worked and said that the illustrations were helpful; $35(25 \%)$ said the active learning exercise was excellent, and 105 (75\%) said the panel board was good. The presentation of the panel board was not graded as regular or poor by any of the students (Table 1).

By analyzing the students' grades obtained through the pretest and posttest, we could verify that the game significantly improved their knowledge about the subject. In group A (students who answered test A as pretest and test B as posttest), the median of grades was $7.07(+/-2.30)$ on the pretest and $8.78(+/-1.20)$ on the posttest $(\mathrm{p}<0.001)$. In group B, (students who answered test B as pretest and test $\mathrm{A}$ as posttest) the median of correct answers was $7.15(+/-1.90)$ on the pretest and $8.99(+/-0.9)$ $(\mathrm{p}<0.001)$ on the posttest. There was no statistically significant difference between groups $\mathrm{A}$ and $\mathrm{B}$. When only students who had not studied the recommended literature before playing the game $(25 \%)$ were analyzed, the difference in students' grades remained significant $(5.90+/-1.90$ as compared with $8.49+/-$ 1.12 [groups A and B]). The same occurred with the 105 students who had read about regulation of the immune response previously $(7.57+/-2.1$ as compared with $8.91+/-1.08$ [groups A and B]) $(\mathrm{p}<0.001)$. 
Da Rosa ACM, Osowski LF, Tocchetto AG, Niederauer CE, Andrade $\mathrm{CMB}$, Scroferneker ML. An alternative teaching method for the regulation of the Immune response

\section{Discussion}

Immunology is taught in the fourth semester at the School of Medicine of Universidade Federal do Rio Grande do Sul (UFRGS). During this period, students begin to interact directly with patients and start their medical practice. As a consequence, their attention towards seminars dealing with the basic molecular and cellular mechanisms of immunology is diverted. Based on this experience, we have developed different alternatives so as to improve learning.

Our data show that the panel board is a useful teaching aid, playing a significant role in the teaching-learning process, even on the medical students who had not read the recommended literature. Students are constantly exposed to a large amount of information in different fields or areas; therefore, a method that uses logical and active-learning material provides more consistent memorization, as shown in the results of our study.

The use of creative illustrations and the division of students into small groups enhances students' engagement, thus promoting their participation, increasing their interest and making the elucidation of pertinent doubts more accessible.

We could verify that the game significantly improved students' grades on the posttest as compared with the pretest. The good results obtained show the importance of using the panel board when trying to approach a subject that is vast and complex not only for students but also for professors. The panel was an interesting tool that certainly helped the monitors to get better prepared for the presentation of the seminar, making the activity more dynamic.

A limitation of our study is that there was no comparison with students' grades from past sessions when we did not use this teaching method. Unfortunately, we did not keep register of students' grades in past years to compare with grades after the introduction of this activity. Other papers that describe the use of games as educational tools ${ }^{2-4,6,7}$ also found positive results despite no comparison with students' performance in previous years. This assures that students' opinion is a valuable evaluation parameter.

Another issue that could be considered a confounding factor refers to the effect of the review session on the learning process. It is possible that this activity increased students' learning, but as we did a pretest after the review session we assumed that students' knowledge was evaluated up to that moment. After that activity, students were influenced only by
Med Educ Online [serial online] 2003;8:13. Available from http://www.med-ed-online.org

the game itself. So, results observed on the posttest reflect basically what students learned during the game.

Also, we would like to comment about possible differences in students' performance that could be based on the performance of the monitor who taught them. Obviously, there are differences between people in terms of ability to explain and expose ideas and these variations can influence students' learning. We tried to minimize these differences by running training sessions for all the monitors. Anyway, we did not verify whether there was any significant variation between the small groups that could be attributed to the monitor's performance.

Finally, we think that this game could perfectly be adapted to a CD-ROM version to be used by students as an additional learning tool at home. Given that only $25 \%$ of students rated the game as "excellent", we believe that this computerized version would probably increase students' enthusiasm about the game.

Despite these few limitations, the game proved to be an important teaching aid. Students were challenged to learn immunology from a different perspective by interacting with monitors and working $\mathbf{b}$ gether with other students. It required all individuals involved to listen actively, not interrupt, encourage others, be open-minded, provide active feedback, and show respect for others even during a competitive activity such as a game. This is an important component because job opportunities in the future will equire employees to work cooperatively to solve problems and develop solutions. As commented previously in another paper" "The best teaching tools are those which make you feel like they aren't teaching tools".

\section{Conclusion}

As previously described, most students endorsed the use of panel boards as an alternative teaching method. The panel boards enable global understanding of the subject matter, helping to consolidate knowledge schematically and to elucidate complex concepts such as regulation of the immune response. In addition, the presentation of the panel boards was effective, and achieved the expected goals.

Games are an alternative way of teaching that helps students, as demonstrated in previous studies, in the field of medical biochemistry and immunology. A large part of the medical curriculum may be explored using active-learning exercises. New teach- 
Da Rosa ACM, Osowski LF, Tocchetto AG, Niederauer CE, Andrade $\mathrm{CMB}$, Scroferneker ML. An alternative teaching method for the regulation of the Immune response

ing methods can be developed for easier learning of tedious medical topics.

We believe that the goals and objectives were accomplished. Moreover, we hope to incorporate other difficult topics in Immunology.

\section{Acknowledgments}

Thanks to the monitors (demonstrators) of the Medical Immunology Course, CBS 06624, from the Universidade Federal do Rio Grande do Sul for their help in conducting the Immune System Regulation game. Also, thanks to Gilson Mattos for revising the English translation of the manuscript.

\section{References}

1. Goldsby RA, Kindt TJ, Osborne BA. Immunology. 4th edition; chapter 11, pp 269-300. New York: W.H. Freeman and Company, 2000.

2. Scroferneker ML, Soria FHC, Shiba AS. An Alternative Teaching Method for the Complement System. Biochemical Education 1995; 23: $67-68$

3. Colombo D, Fritsch A, Ordovás KG, Spode A, Scroferneker ML. Playing with Cellular and Humoral Immunity. Biochemical Education 1998; 26: 20-21.

4. Siqueira AJS, Remião JOR, Azevedo AM. Metabolograms to teach biochemistry. Biochemical Education 1988; 16:20-22.
Med Educ Online [serial online] 2003;8:13. Available from http://www.med-ed-online.org

5. Siqueira AJS, Remião JOR, Azevedo AM. Dynamic metabolic diagrams in biochemistry. Biochemical Education 1992; 20: 9798 .

6. Baldor RA, Field TS, Gurwitz JH. Using the "Question of Scruples" Game to Teach Managed Ethics to Students. Academic Medicine 2001; 76 (5): 510-511.

7. Moy JR, Rodenbaught DW, Collins HL, Dicarlo SE. Who wants to be a physician? An Educational Tool For Reviewing Pulmonary Physiology. Adv Physiol Educ 2000; 24 (1): 3037.

8. Wraith D, Roitt I. Immunology. St. Louis: Mosby, 2001.

9. Scroferneker ML, Pohlmann PR. Imunologia Básica e Aplicada. Primeira edição, pp.218-237. Porto Alegre: Sagra Luzzatto, 1998.

10. Abbas A, Lichtman AH, Pober JS. Cellular and Molecular Immunology. 4th ed. pp. 208-231. Philadelphia: Saunders, 2000.

\section{Correspondence}

Maria Lúcia Scroferneker, Rua Vasco da Gama 176/604 Porto Alegre - RS - Brazil. CEP 90420-111

E-mail: scrofern@ vortex.ufrgs.br 
Appendices 


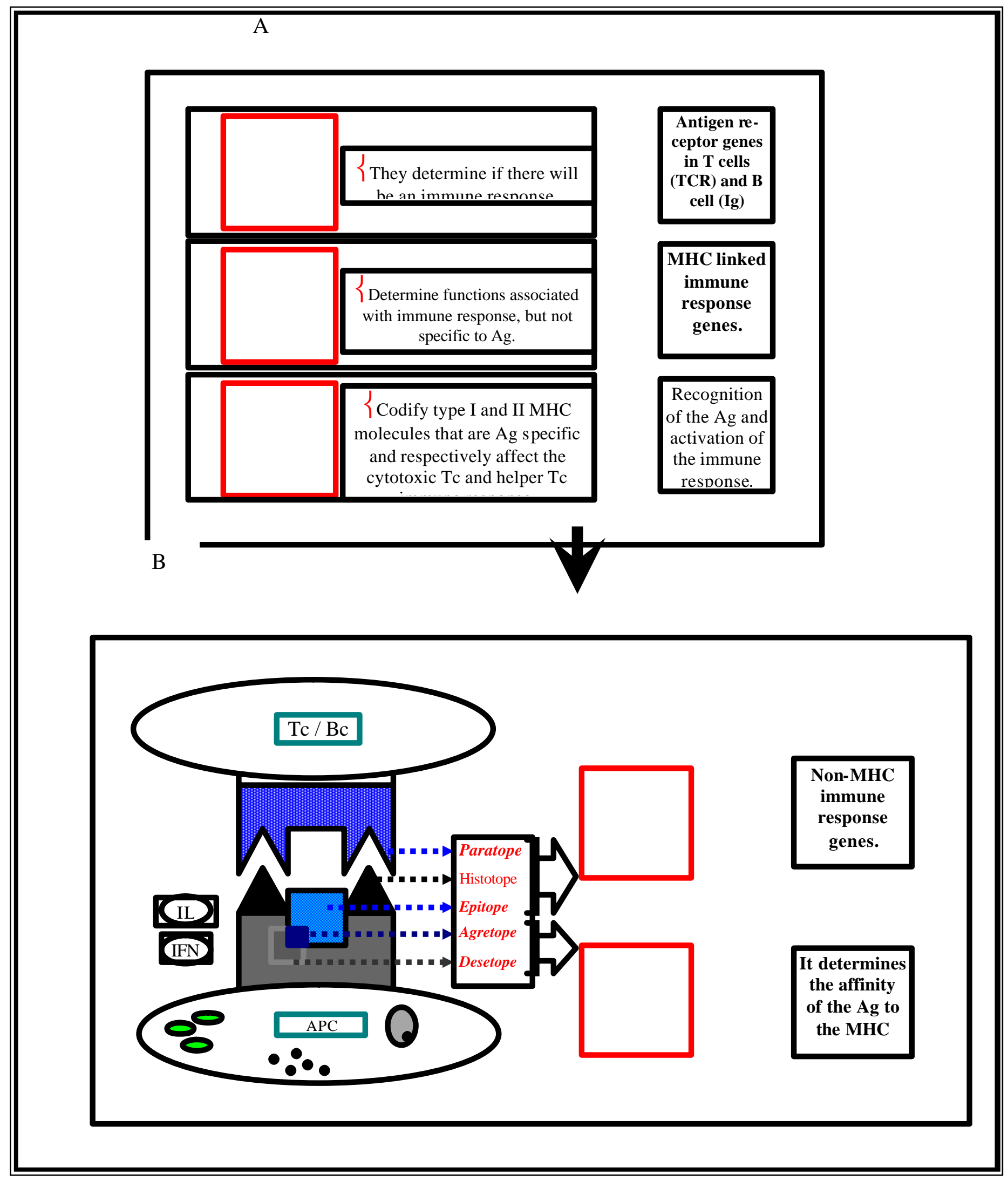

Figure 1 - Panel about genetic control: in A, genetic groups and their respective functions; in B, parts of the receptor site involved in antigen presentation and their respective regulation genes. 


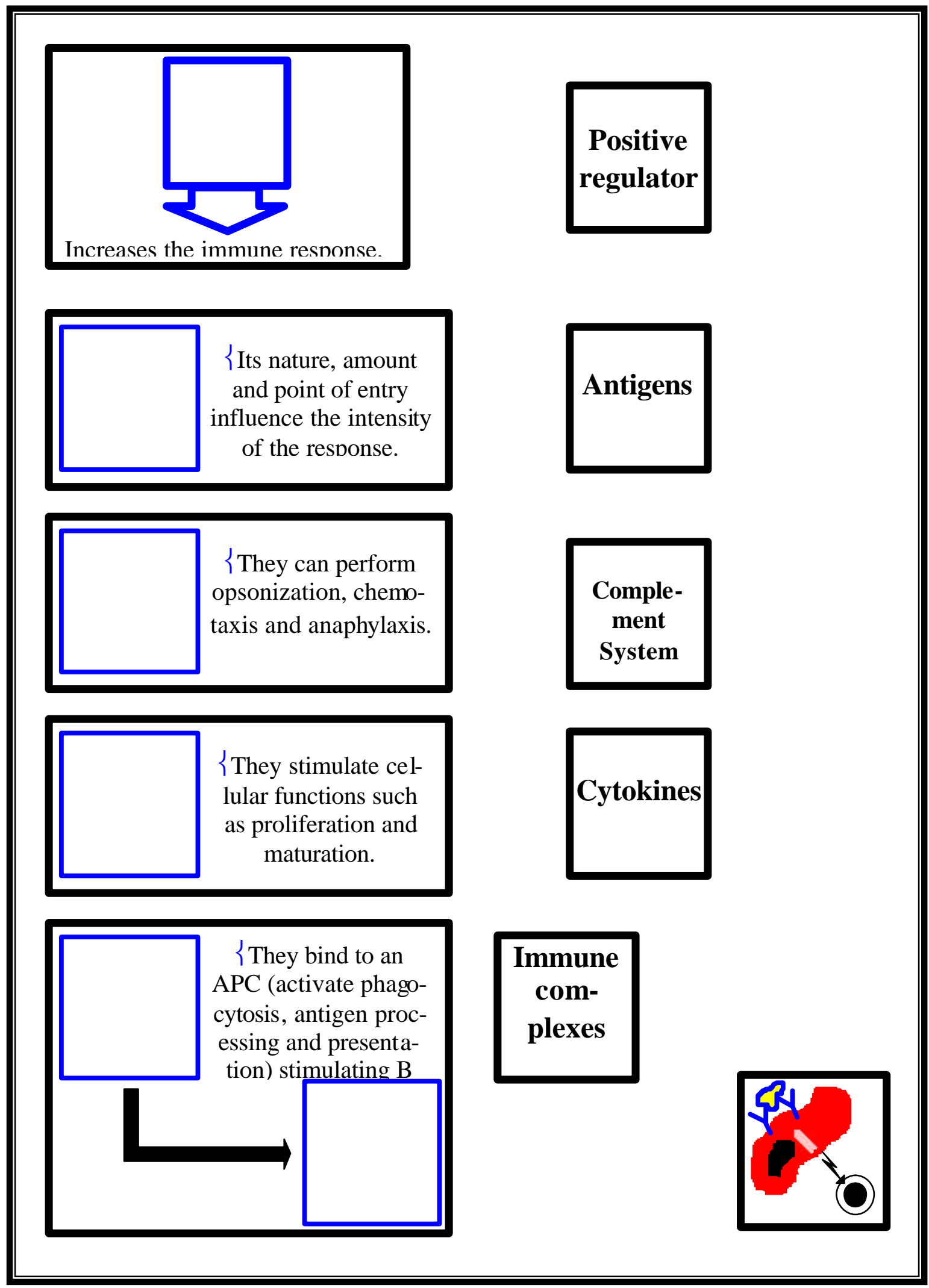

Fig. 2 - Panel about positive regulation. 

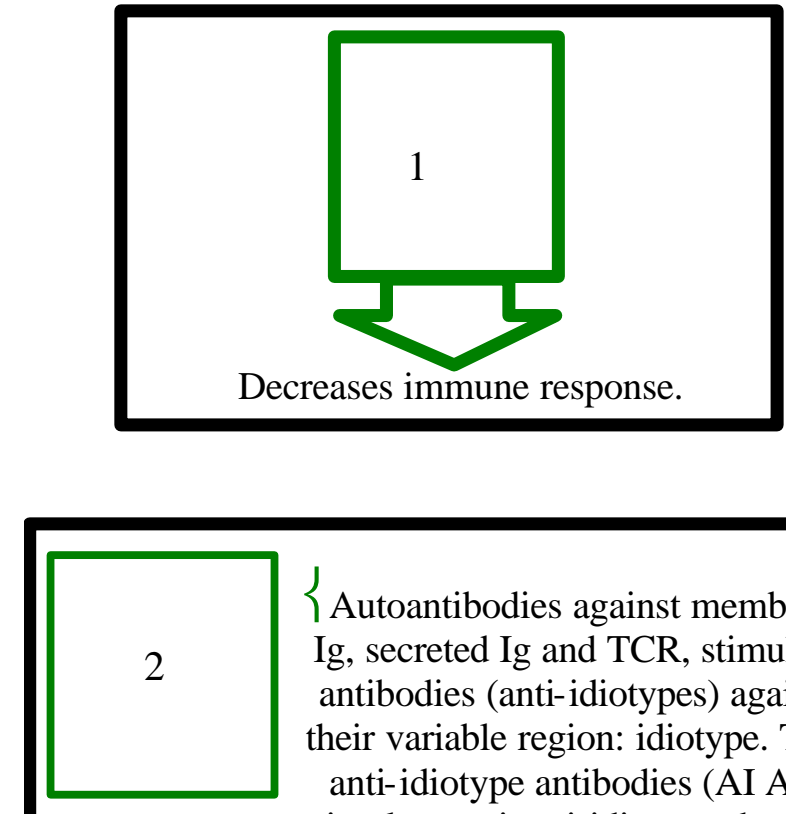

$\{$ Autoantibodies against membrane Ig, secreted Ig and TCR, stimulate antibodies (anti-idiotypes) against their variable region: idiotype. This anti-idiotype antibodies (AI Ab) stimulate anti-anti-idiotypes but in a decreasing concentration, until the amount of antibodies is not enough

to mainta in the network.
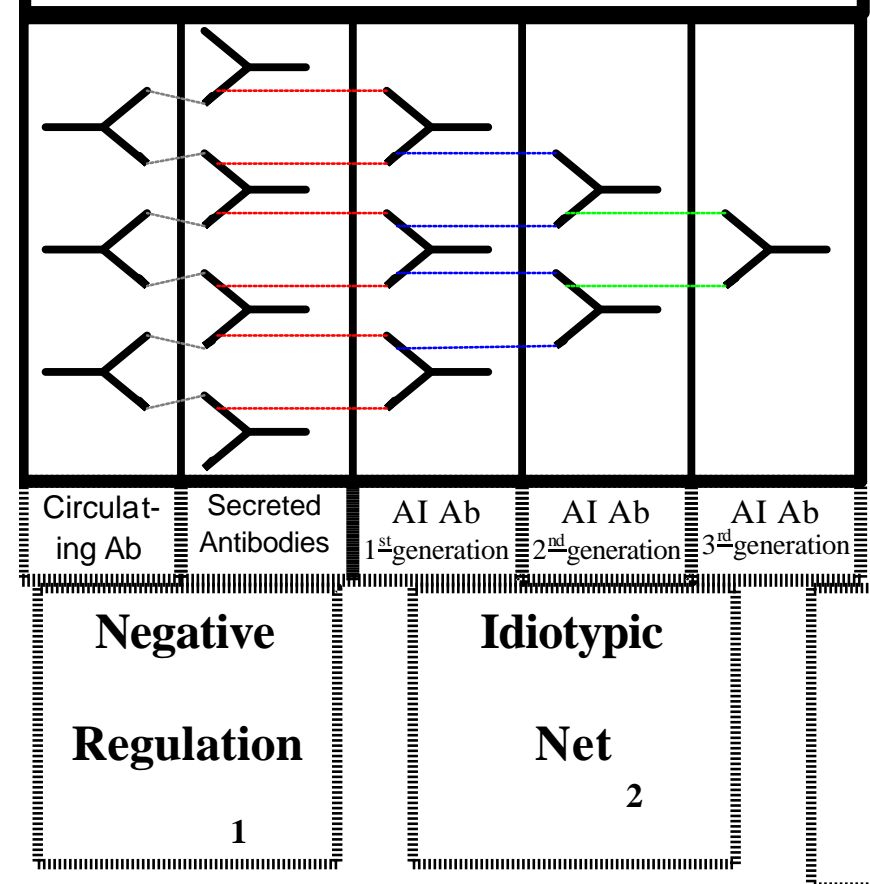

(1)

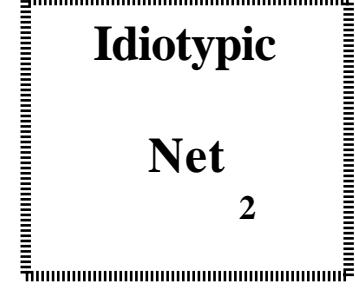

辜

Natural Killer Cell

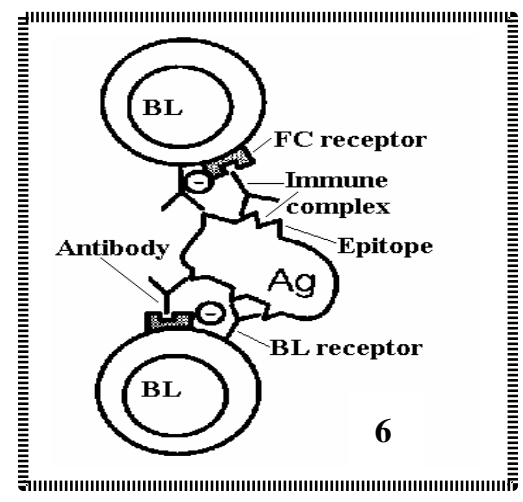

$\left\{\right.$ These cells are $\mathrm{CD}^{+}$and $\mathrm{CD}^{-}$or $\mathrm{CD}^{-}$and $\mathrm{CD} 4^{+}$. They can act by direct competition for stimulation factors, direct cytotoxicity to $\mathrm{Bc}$ or $\mathrm{Tc}$ and by production of suppressor factors.

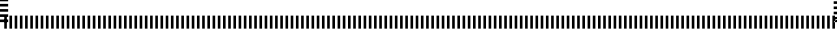

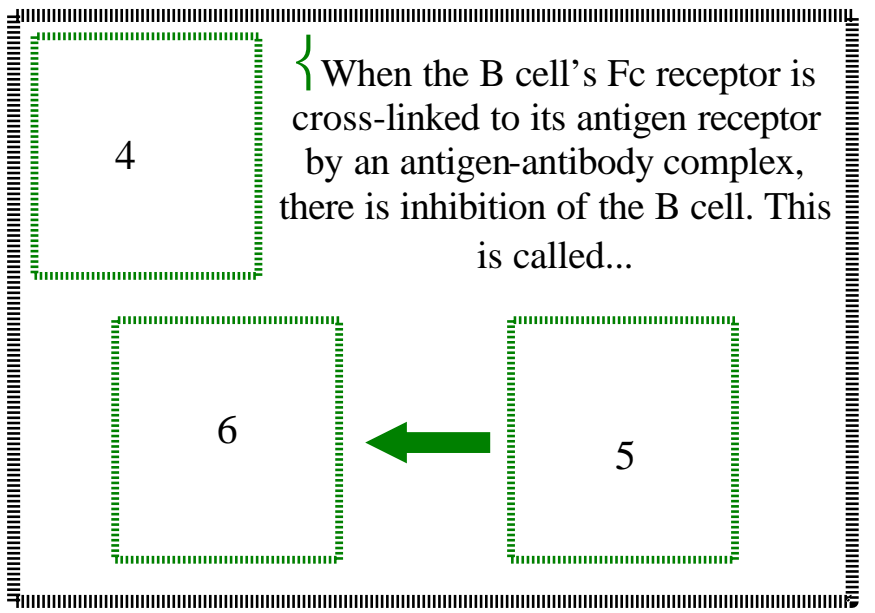

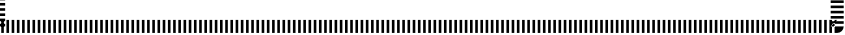

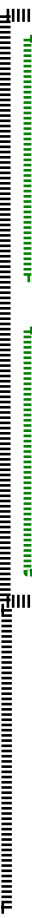

$\{$ They can suppress the production of antibodies through direct elimination of the antigen or...

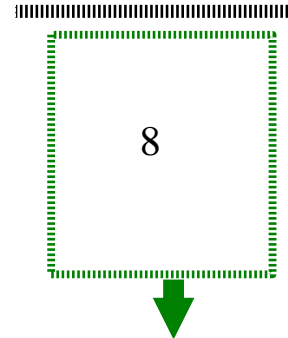

Antibodies block the interaction between the epitopes of an antigen, an Ig (B cell receptor) or TCR (T cell receptors), which become unable to recognize the antigen.

9

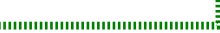

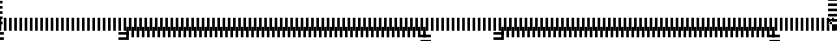

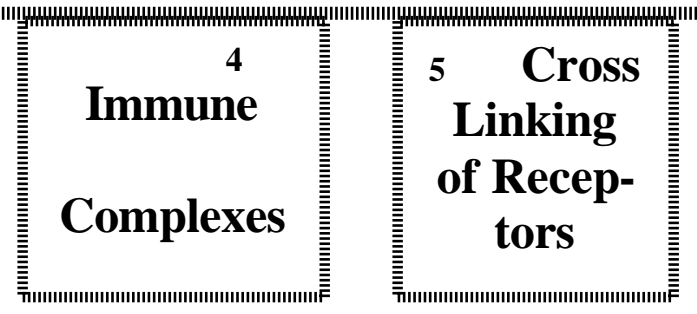




\section{UNIVERSIDADE FEDERAL DO RIO GRANDE DO SUL DEPARTMENT OF MICROBIOLOGY MEDICAL IMMUNOLOGY COURSE CBS - 06624}

TEST A

REGULATION OF THE IMMUNE RESPONSE

Name: Date:

1. ( ) The nature of the antigen, its dose and route of administration influence the type and magnitude of the immune response.

2. ( ) The antigen presentation carried out by professional APCs, which express large amounts of MHC II and costimulatory molecules, works as a negative regulatory mechanism of the immune response.

3. ( ) Polysaccharide and lipid antigens are the most powerful immunogens, inducing both cellular and humoral immunity.

4. ( ) The presence of maternal IgG, at the time of vaccination, may avoid the development of a protective response in a child.

5. ( ) Antibody feedback consists of the bond between the antibody and the antigen in a competitive manner with surface receptors of B cells. 
6. ( ) The administration of antiRh antibody in the immediate puerperium to an Rh-negative mother prevents primary sensitization to the positive $\mathrm{Rh}$ of the fetus, since the antibodies given passively bind to the antigen, competing with B cells.

7. ( ) Suppressor T cells, which negatively modulate their own expression, are always CD8+ and CD4.

8. ( ) Anti-idiotypic antibodies are those that bind to various regions of immunoglobulins and TCRs.

9. ( ) Corticosteroids, released during stressful situations, have an immunostimulatory action.

10. ( ) Stressful conditions may lead to the suppression of immune functions, thus reducing the capacity of an individual to recover from an infection. 


\section{UNIVERSIDADE FEDERAL DO RIO GRANDE DO SUL DEPARTMENT OF MICROBIOLOGY \\ MEDICAL IMMUNOLOGY COURSE CBS - 06624}

TEST B

REGULATION OF THE IMMUNE RESPONSE

Name: Date:

1. ( ) The subcutaneous or intradermal inoculation of antigens does not often induce an immune response.

2. ( ) The nature of the antigen, its dose and route of administration influence the type and magnitude of the immune response.

3. ( ) The absence of costimulatory molecules on the surface of antigen-presenting cells results in the ineffective activation of $\mathrm{T}$ lymphocytes and could lead to tolerance.

4. ( ) Antibodies given passively bind to the antigen, competing with B cells.

5. ( ) T-helper lymphocytes are subdivided into 2 populations according to the production of cytokines. Th2 negatively regulate the intensity of immune response through the secretion of IL-10.

6. ( ) Antibody feedback is a mechanism whereby IgG antibodies inhibit the differentiation of B cells by cross-linking the antigen receptor with the Fc receptor on the same cell. 
7. ( ) Anti-idiotypic antibodies are those that bind to constant regions of immunoglobulins and TCRs.

8. ( ) The levels of maternal IgG remain high in children at least during the first six months of life. Children vaccinated within this period usually need several supplemental doses.

9. ( ) The immunosuppressive effect of corticoids released during stressful situations is one of the examples of functional interaction between the immune and the neuroendocrine systems.

10. ( ) The capacity to respond to a certain antigen is inherited and therefore varies among individuals. 